\title{
Conception Age
}

National Cancer Institute

\section{Source}

National Cancer Institute. Conception Age. NCI Thesaurus. Code C114088.

The time elapsed between the day of conception and the day of delivery. 